\title{
DO IMPERATIVO DA AVALIAÇÃO: espelhos distópicos da contemporaneidade
}

\section{Maria Cristina Franco Ferraz}

Universidade Federal do Rio de Janeiro, Rio de Janeiro, Rio de Janeiro, Brasil

\section{Resumo}

Partindo da análise do primeiro episódio da terceira temporada da série Black Mirror ("Queda livre"), o artigo investiga a lógica de funcionamento do dispositivo da avaliação, atrelada às mídias sociais. Tematiza as tecnologias não como causa, mas em sua adequação a modos de vida atravessados pelo capitalismo financeirizado e pelo modelo empresarial. Remete ao "diagrama da avaliação" (José Gil), em seus mecanismos de exclusão nuançada, bem como às reflexões de Büttgen e Cassin acerca da avaliação de desempenho acadêmico. Por fim, distingue o diagrama da avaliação do sentido nietzschiano de avaliação, radicalmente diverso do "julgamento" de cunho moral, midiático e político.

\section{Palavras-chave}

Black Mirror. Diagrama da avaliação.

Filosofia nietzschiana.

\section{Introdução}

Em outubro de 2016, um episódio do seriado norte-americano Black Mirror - à época recém-adquirido pela Netflix - enfatizou um fenômeno cada vez mais presente em modos de vida hiperconectados, permanentemente on-line, ancorados no desenvolvimento e na disseminação de redes de informação e comunicação em suportes digitais. O título em inglês, "Nosedive", alude a um mergulho de ponta cabeça e foi traduzido em português como "Queda livre". Trata-se do primeiro episódio da terceira temporada do programa. Dirigido por Joe Wright, enfatiza os infernos da avaliação onipresente, horizontalmente acionada por todo o tecido social. Explicitamente distópico, esse episódio serve como ponto de apoio para alavancar certas reflexões acerca das relações entre a expansão de modos de vida empresariais, a conectividade em "tempo real" e a disseminação do imperativo da avaliação.

Na trama, a fim de ascender em seu trabalho e em sua inserção social, a personagem central, Lacie Pound (interpretada por Bryce Dallas Howard), dedica-se integral e tenazmente 
a aproximar-se da pontuação virtual superior (5 estrelas), na média das notas a ela atribuídas por qualquer um com quem cruze ou com quem literalmente esbarre. Entretanto, por mais que se esforce, Lacie sofre o infortúnio de ver despencar sua avaliação de maneira irrecorrível, por conta de pequenos incidentes triviais e incontroláveis. Atualizada minuto a minuto, sua "qualificação" e seu ranqueamento funcionam como marcadores identitários privilegiados, ou mesmo únicos. Isso define todo o espectro de suas relações sociais, à exceção de um único vínculo mais íntimo com o irmão, não muito bem avaliado e crítico com relação à verdadeira compulsão avaliativa da irmã.

Figura 1: Pontuação inicial da protagonista Lacie Pound, acessível pelo celular

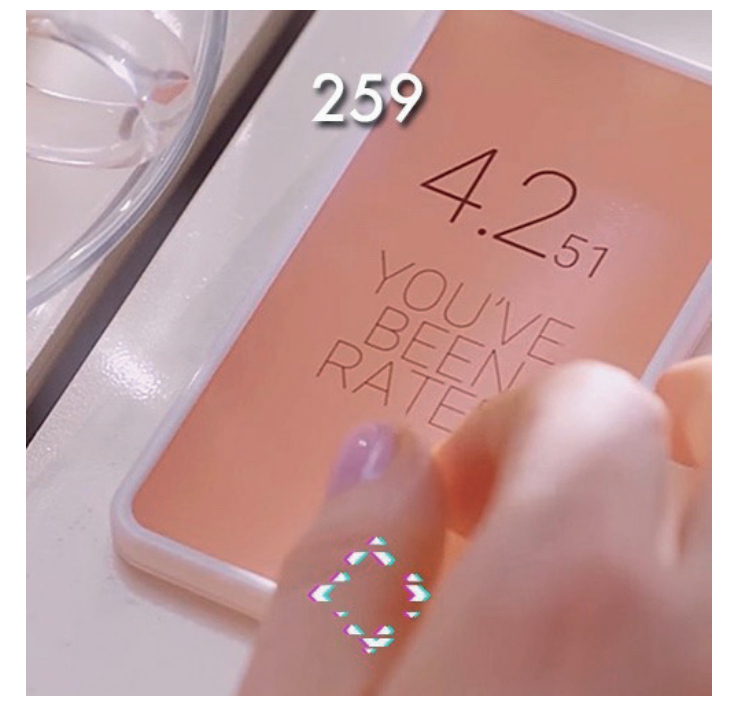

O grau de pontuação determina o acesso, ou não, tanto a postos de trabalho quanto a espaços da cidade. Determina ainda a frequentação de certas camadas sociais privilegiadas. Na trama, sua pontuação interfere, por exemplo, na obtenção de um aluguel promocional e de um assento em um voo lotado, bem como em sua inclusão como dama de honra no casamento de uma amiga de infância, tola, rica e muito bem avaliada. A fim de conquistar pontos em sua avaliação, Lacie termina por consultar um especialista, uma espécie de expert e coach, que analisa, por meio de gráficos, suas relações sociais e aconselha ações e modos de ser para dar um "boost" (impulso) no ranqueamento da personagem. Em inglês, a empresa a que recorre chama-se Reputelligent. Conforme fica evidenciado, práticas e lógicas do modelo empresarial de vida foram integralmente incorporadas nessa sociedade "futura". 


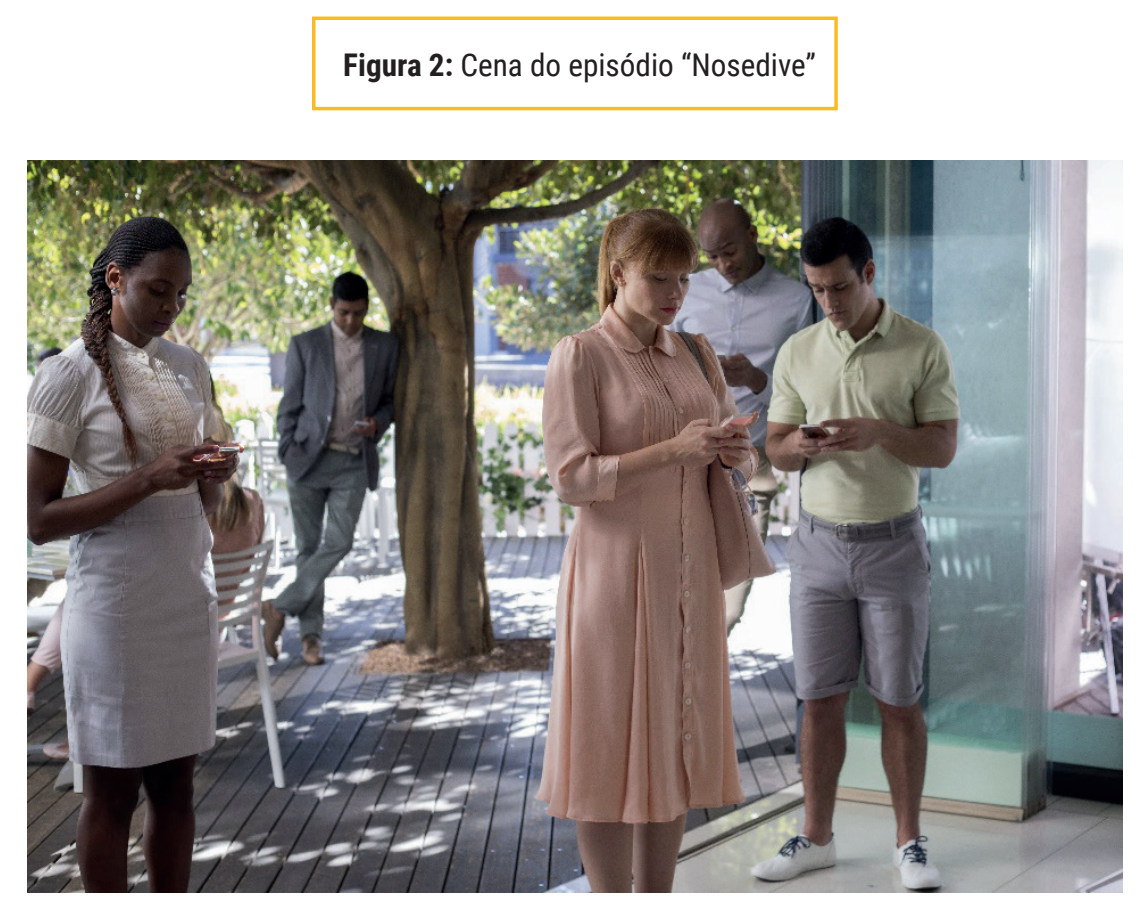

O olhar judicativo do outro, especular, insere-se na trama do episódio de modo direto: uma lente acoplada aos olhos tanto acompanha, no espelho, a própria pontuação quanto, dirigida para os outros, tem acesso imediato à nota alheia. Parece terem-se fundido, portanto, o olhar judicativo e o brilho negro das telas virtuais. O julgamento adquire a dimensão de um pesadelo kafkiano. Porém, não mais, como em Kafka, por conta dos meandros esmagadores do poder burocrático moderno, mas sob a forma de uma rede bem mais sutil e, por isso mesmo, mais eficaz e violenta. Os cliques imediatos do episódio - não muito distantes dos likes ou dislikes instantâneos que abundam no Facebook - refletem a incorporação e a naturalização, em (quase) todos os membros da sociedade, de uma implacável lógica de exclusão. Esse olhar que julga e atribui notas foi definitiva e ironicamente estendido a todos; ou seja: foi "democratizado". No episódio, as notas são em geral disparadas apontando-se o celular como uma arma em direção ao outro.

No final, após a "queda livre" da personagem, quando Lacie vai presa, é de imediato destituída do celular. As lentes avaliadoras acopladas a seus olhos são extraídas. Curiosamente, então, ela passa a ver o prisioneiro negro na cela da frente. No entanto, o gesto de apontar contra o outro a arma da avaliação persiste inscrito em sua mão, despojada do celular.

É necessário ressaltar que esse regime onipresente de avaliação não é um mero efeito das redes sociais tecnologicamente mediadas. Abordar a questão a partir de uma 
visada causalista implicaria considerar as redes sociais e as próprias tecnologias digitais como isoladas em um plano à parte para, a seguir, tratá-las como intrinsecamente determinantes. Em vez de trabalhar com a lógica causa/efeito, supondo uma autonomia das tecnologias para tomá-las como "causas" de fenômenos sociais e subjetivos, trata-se de tematizá-las seguindo a lição de Foucault e de Crary (FOUCAULT, 1980; CRARY, 1999; FERRAZ,
2015) - simultaneamente como efeitos e instrumentos de determinadas formações históricas. Postular "efeitos" desentranhados da busca por "causas" é um gesto primordial do método genealógico, proposto por Nietzsche e desenvolvido por Foucault. Como máquinas são, antes de tudo, sociais, elas exprimem determinadas formações sociais em que emergem. Ao mesmo tempo, interferem e produzem efeitos nessas mesmas formações históricas.

Figura 3: Ao final, presa e privada de seu celular, Lacie aponta a arma avaliadora para outro prisioneiro

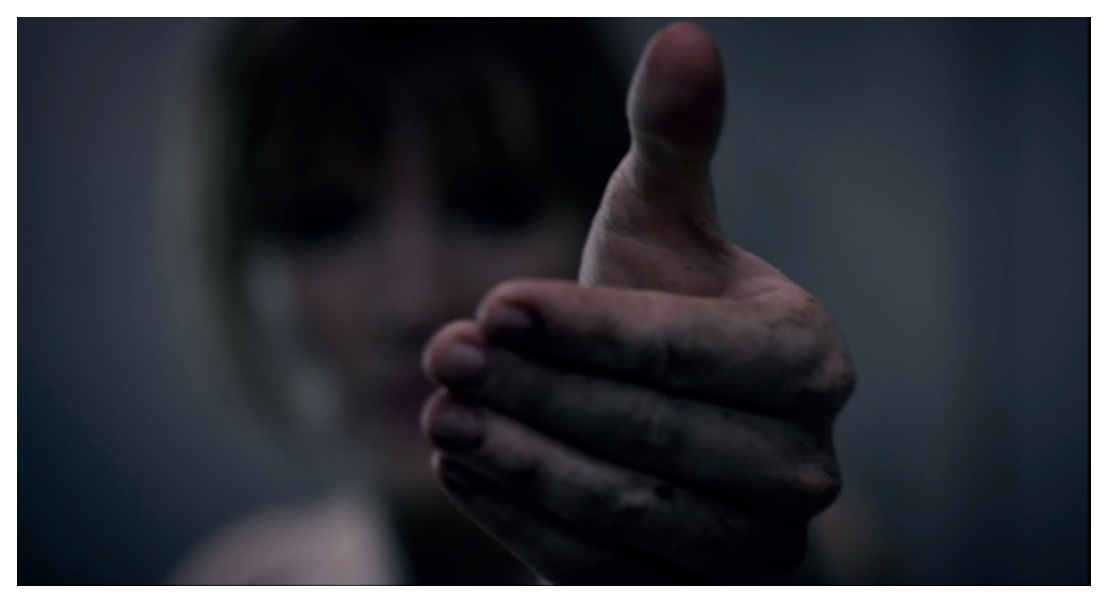

Seguindo essa linha de reflexão, podemos afirmar que são os dispositivos de avaliação em tempo real que se coadunam com modos de vida adequados à determinada sociedade. Ao mesmo tempo, eles os favorecem e intensificam. Com efeito, a avaliação contínua alimenta os mecanismos de funcionamento do jogo excludente incrementado pela expansão do capital financeirizado, que prescinde da necessidade de anexar a totalidade (ou a maioria) dos corpos a seus sistemas de acúmulo e consumo. Entre tecnologias e vida social, trata-se, portanto, de vínculos de compatibilidade ou de adequação; não de causalidade. A tendência usual permanece, geralmente, a de atribuir aos meios tecnológicos a instância causal de fenômenos sociais 
- o que simplifica o problema e, por isso mesmo, tende a fechar a questão, estancando a necessidade de problematização. O episódio de Black Mirror do qual partimos pode se prestar a essa leitura. Por isso cabe a ressalva aqui indicada.

No episódio "Queda livre", o que se "avalia" mal? Sobretudo a emergência ou a explosão inadvertida de afetos espontâneos e agressivos, como sentimentos de raiva, incômodo, desassossego (e reivindicações). Nada mais compatível com uma cultura na qual o sorriso compulsório do ícone Smiles expressa com propriedade a ditadura da imagem da felicidade espetacularizada na superfície dos rostos e a pressão pelo sucesso individual. Essa imagem de aquiescência total, indicativa de sucesso e "autoestima", remetida ao pequeno grupo de "vencedores" (FREIRE FILHO, 2010), torna literalmente obscenos sofrimentos, agruras, fracassos e tensões sociais. A imagem do ícone Smiles aparece explicitamente em um momento do episódio "Queda livre": Lacie toma um café, acompanhado de um biscoito com a tal carinha sorridente, que ela fotografa certamente para compartilhar. Antes disso, treina sorrisos gentis em frente ao espelho de casa. A figura Smiles - igualmente implicada no autoritário e cínico "sorria, você está sendo filmado" - pode ser associada à violência predatória do sorriso-esgar Mickey revelado, pelo menos desde o início do século XXI, em filmes como Mulholland Drive (Cidade dos Sonhos, 2001), de David Lynch.

Figura 4: Ícone Smiles a ser literalmente ingerido em "Nosedive"

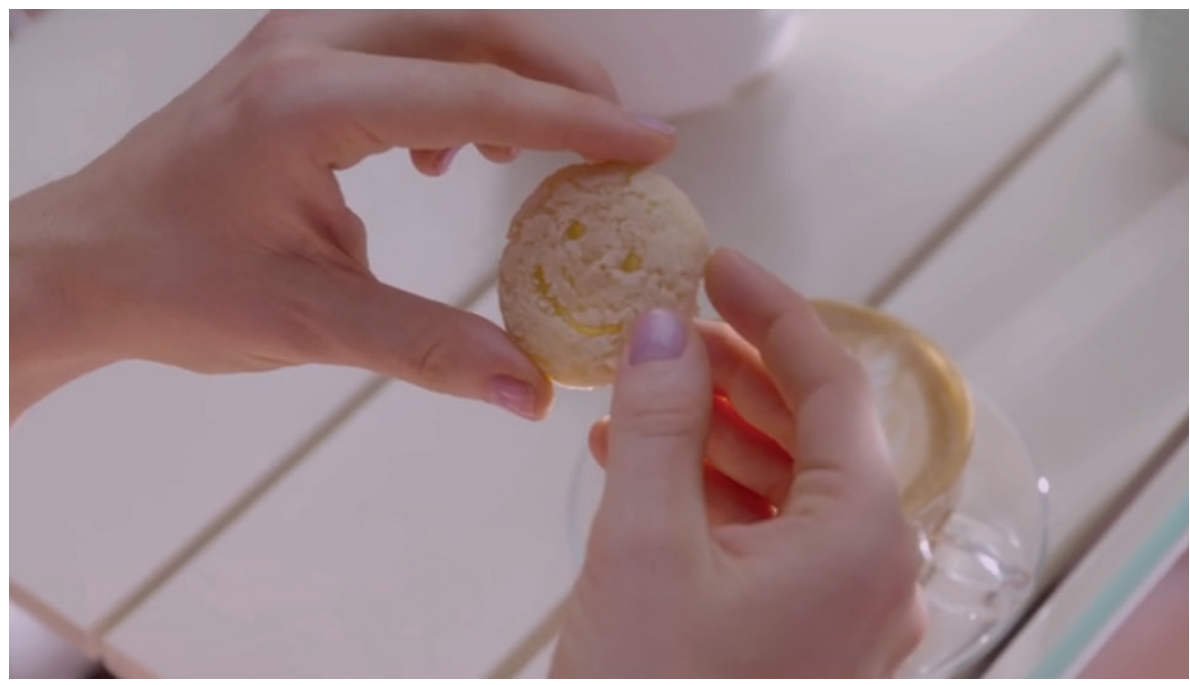


O espaço urbano em que "Queda livre" se situa lembra também o contentamento aparente e apaziguador aliado às delícias do consumo, em shoppings, malls e condomínios - como o do filme de Tim Burton "Edward, mãos de tesoura" (1990). Em geral, trata-se de ambientes limpos, clean, em tons pastéis, higienizados de fricções e rugosidades sociais, com seus moradores exibindo expressões de felicidade e, em geral, de cordialidade. No episódio, os tons suaves do mobiliário, das casas e do vestuário corroboram essa visão clean e amortecedora. Lacie está sempre se vestindo de rosa bebê ou de azul clarinho. Aliás, as imagens do episódio são banhadas, sobretudo na parte inicial, por tons róseos pop, chamados de "Millenial Pink". Há igualmente elementos retrô nos figurinos e cenários, alusivos à entronização e ostentação do bem-estar e da felicidade que, desde o pós-guerra, foram intensamente propagandeados tanto pela Cidade dos Sonhos americana (Hollywood) quanto por reluzentes apelos visuais publicitários.

Ao longo do episódio, Lacie exprime a angústia provocada pela injunção de ter de se mostrar sempre bem, ou mesmo "mais do que bem" (BEZERRA JR, 2010). Dedica-se com afinco, e não sem violência contra si mesma, ao espetáculo da otimização do humor e da positividade, tomados igualmente como indícios de uma vida realizada e de uma saúde robusta. Não há lugar para o desassossego ou para o mal-estar - temas caros à modernidade, se pensarmos em Bernardo Soares e Freud. Consequentemente, tampouco há lugar para críticas e tensões. Imperam, no entanto, uma luta e uma disputa ferozes com todos outros por uma pontuação que fará a personagem superar, em definitivo, sua associação com mal avaliados e potencialmente excluídos. A personagem só irá encontrar ajuda, e certa solidariedade, no campo dos excluídos, como é o caso, por exemplo, da motorista do caminhão que lhe dá carona quando, em plena queda livre, Lacie fica a pé na estrada em direção ao casamento da amiga. Significativamente, após ser presa e liberada do jugo avaliativo, irá esbravejar e trocar insultos liberadores com o prisioneiro negro da cela à sua frente.

Mecanismos de avaliação estão evidentemente presentes em redes sociais, como o Facebook, no qual se vai naturalizando o hábito de curtir ou descurtir uma postagem, um perfil, o que induz a se contabilizar a sensação de sucesso, a medir taxas de credibilidade ou índices de fracasso. Pequenos hábitos cotidianos tendem a ser incorporados de modo a se tornarem cada vez mais naturalizados e, portanto, imperceptíveis. Por exemplo, em serviços de transporte como o Uber, avaliamos (e somos avaliados) com até cinco estrelas - como em "Queda livre" - o motorista que trabalha sem contar com as antigas redes de proteção conquistadas no regime de trabalho assalariado. 


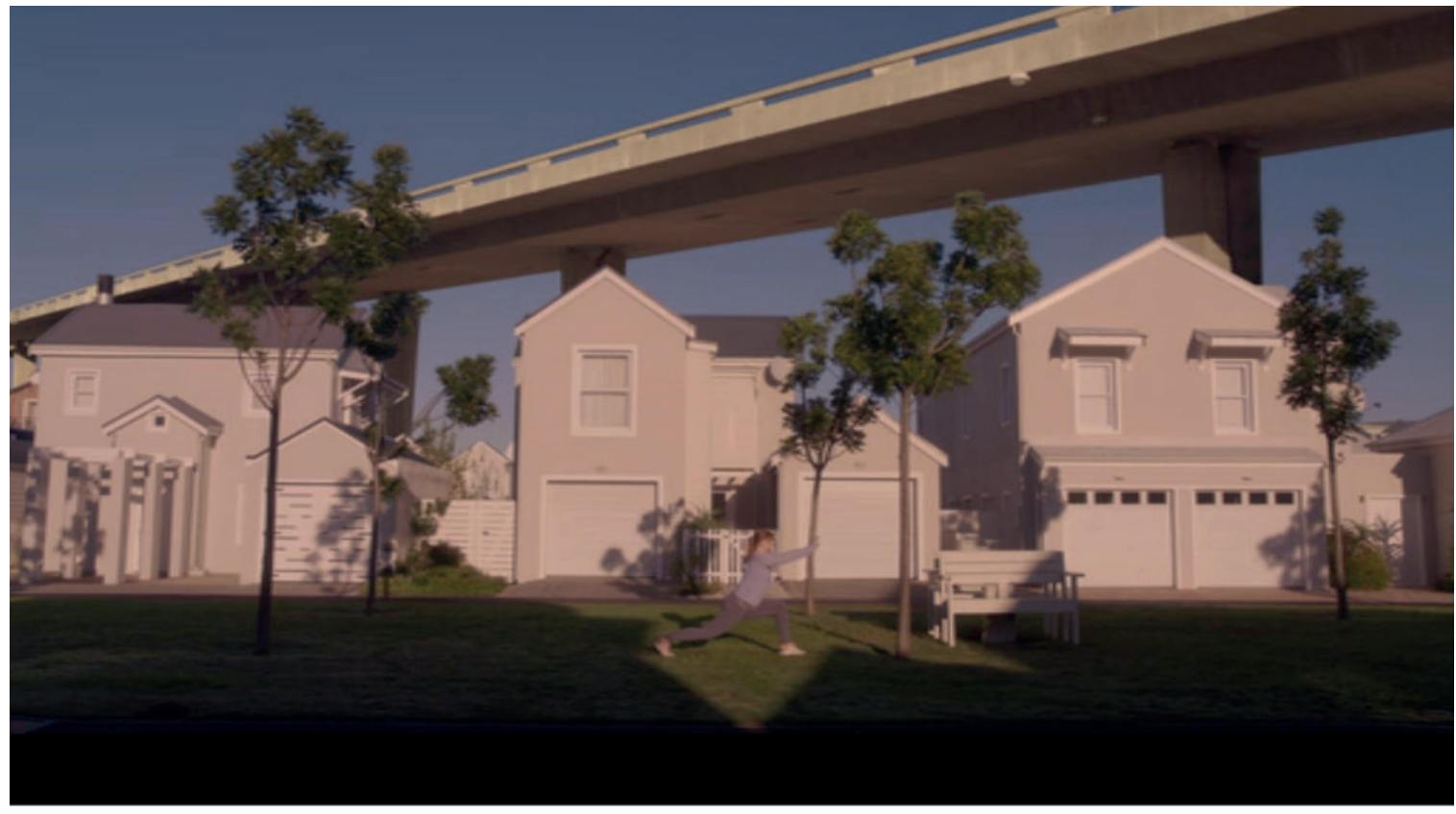

Conforme já salientamos, não é o aplicativo que determina essa lógica; este é, antes, adequado à política de desregulamentação e flexibilização de regras de trabalho e de serviços, que passam a prescindir do controle de um chefe ou de um supervisor. Todos se tornam esse antigo "chefe", que se exime da tarefa de cobrança. O próprio aplicativo contabiliza as avaliações que os usuários em geral não deixam de efetuar e de enviar, em uma espécie de mobilização geral em favor do poder de julgar o outro, de avaliá-lo e, indiretamente, de lhe conceder (ou lhe retirar) condições de trabalho. Não estranha que os motoristas ligados a esse tipo de aplicativo tenham de ser mais afáveis do que os motoristas de táxis convencionais. No caso de Black
Mirror, o seriado também disponibiliza um aplicativo ("RateMe") em que os espectadores podem avaliar seus amigos, tal como no episódio. Aliás, a própria Netflix permite que seus usuários avaliem os filmes/séries a que assistiram, também no modelo de uma a cinco estrelas, aumentando ou diminuindo a popularidade do vídeo no interior da plataforma.

Para avançar as discussões acerca do dispositivo da avaliação e das implicações de sua disseminação nos modos de vida atuais, retomarei aqui reflexões já desdobradas por alguns filósofos, sintetizadas em um trabalho apresentado no xxili Encontro Anual da Compós, em 2014 e em um capítulo do livro Ruminações: cultura letrada e dispersão 
hiperconectada (AUTOR, pp.15-30). A primeira referência remete ao livro Em busca da identidade (o desnorte), de José Gil (GIL, 2009). Inspirado na biopolítica foucaultiana e no conceito deleuzeano de controle, José Gil sugere que a figura emblemática do século XXI, especialmente nas sociedades liberais avançadas, seria a do "homem avaliado" (GIL, 2009, p. 52). Essa noção proposta pelo filósofo português dialoga com a de "homem endividado" que, para Deleuze, teria sucedido o "homem confinado" entre os muros disciplinares. Cabe, de início, explicitar a noção deleuziana.

Segundo Gilles Deleuze (DELEuze, 1992), na disciplina sempre se está recomeçando, fechando e abrindo ciclos, o que sugere a sensação de se ter quitado dívidas entre um confinamento e o subsequente. Sensação ilusória, na medida em que a uma quitação corresponde a contração de nova dívida, em outros módulos disciplinares. Mas, de alguma maneira, tem-se a sensação de conclusão de uma etapa, como, por exemplo, no caso das séries escolares. Nas sociedades de controle, por sua vez, nada se termina ou se conclui, como no caso, por exemplo, da formação escolar. Já não se experimenta a sensação de quitação, mesmo que aparente, como na disciplina. Deleuze contrapõe a lógica operante nas sociedades disciplinares, que funcionam como uma quitação aparente de dívidas em um processo serializado de confinamentos, àquela em funcionamento nas sociedades de controle, aproximável da noção de uma moratória ilimitada, em variação contínua e infinita (DELEUZE, 1992, p. 222). O filósofo assinala de que modo Kafka, por exemplo, amalgamou práticas disciplinares e lógica do controle em sua obra O processo.

O dispositivo da avaliação equivale a uma versão radicalizada desse diferimento perpétuo do endividamento; ele corresponde a uma incrementação do regime de dívidas permanentes, certamente impagáveis, ainda mais intensificadas pela ausência mesma de fim ou "norte" - como diria José Gil. Essa propagação infinita da dívida se exprime, por exemplo, na inquietante lógica da superação permanente. Não por acaso, os interesses do capital financeiro também se organizam em torno do acesso ao crédito - portanto à dívida - de que dependem tanto indivíduos quanto países. Daí a importância da "credibilidade", ou seja, das condições de acesso à dívida. Nesse sistema, ter o privilégio de aceder ao endividamento traça a linha fronteiriça entre o poder consumidor e a exclusão, ou a pobreza.

José Gil salienta que a avaliação não se restringe atualmente ao sistema educativo, mas permeia todo o tecido social, funcionando como um "diagrama transversal a toda a sociedade" (GIL, 2009, p. 52). Em sua condição diagramática, funciona de modo a hierarquizar, 
selecionar, integrar e, sobretudo, excluir. $\mathrm{Ou}$ seja: só integra para estabelecer graus nuançados de exclusão (GIL, 2009, p. 53), tendo por horizonte padrões inalcançáveis e infinitos, o que não poderia deixar de causar angústia. Essa lógica de funcionamento alcança todas as esferas da vida. Articula-se a modos de vida impregnados por valores empresariais, tal como a noção de autossuperação constante, permanente, que tem igualmente por efeito culpabilizar individualmente, como no caso da personagem de "Queda livre", aquele que falha. Deleuze já havia sugerido que, no lugar do "indivíduo" (etimologicamente, aquele que não se divide), tendemos a nos tornar "dividuais", seres cindidos, em eterna competição com os outros e sobretudo com nós mesmos (DELEUZE, 1992, p. 222).

Tal como enfatizado em "Queda livre", o diagrama da avaliação produz sensações de inadequação, fonte de grandes sofrimentos, medicalizados sob o modo de níveis variados de depressão ou como transtornos de ansiedade $^{1}$. A pressão constante das avaliações faz com que se incorpore e naturalize tal imperativo, em vez de se buscar identificar e colocar em xeque a lógica e o regime de vida em que se está inserido. Os excluídos em diferentes graus se convencem de sua própria inferioridade, de seu impoder tanto face ao avaliador quanto ante a nebulosa imagem ideal. José Gil cita as oportunas afirmações de Jacques-Alain Miller, extraídas do livro Voulez-vous être évalué? (Você quer ser avaliado?): "a comparação é, com efeito, o núcleo da avaliação"; "a avaliação visa à autocondenação pelo sujeito" (MILLER apud GIL, 2009, p. 53). A privatização do sentimento de inadequação ou fracasso atenua, ou mesmo anula, a visada crítica, desativando o movimento de transformação. Contínua e ininterruptamente sob avaliação, o "dividual" tende a se medir em termos de sua posição em escalas de performance constantemente atualizadas. Inevitavelmente, os expelidos dessa corrida sem norte tendem a se constituir como legiões.

Eis como procede, conforme José Gil, o diagrama da avaliação: em primeiro lugar, captura forças livres, fixando-as hierarquicamente em relações de poder. Submete então a singularidade do indivíduo a um crivo geral, "em que se comparam, se quantificam e se qualificam competências" (GIL, 2009, p. 53). Como esses padrões estabelecem graus máximos,

Ressalte-se que, segundo dados divulgados pela OMS em 2017, a depressão cresce no mundo, e o Brasil é o quinto país no ranking da depressão, contando com cerca de 11 milhões e meio de casos, sendo apenas superado, em números absolutos, pelos EUA. Ainda segundo a OMS, o Brasil é o campeão em prevalência de transtornos de ansiedade (cf. https://g1.globo.com/bemestar/noticia/depressao-cresce-no-mundo-segundo-oms-brasil-tem-maiorprevalencia-da-america-latina.ghtmlv, visitado em abril de 2017). 
virtualmente infinitos (a dívida impagável) de otimização de competências, induzem necessariamente sentimentos de impotência, insatisfação, angústia e inferioridade.

Esse diagrama atravessa todo o campo social, mas tem se manifestado, de modo bastante direto e tangível, nos âmbitos da educação e da vida acadêmica. Atentemos para a novidade da situação: não se trata do mesmo gesto de avaliar nos moldes da educação moderna, normalizadora e disciplinar, que implicava términos e recomeços serializados: provas, exames, conclusões de cursos, diplomações etc. Conforme antecipou Deleuze (DELEUZE, 1992, p. 224), algo da empresa - sua "alma" - tende a se sobrepor à tradição disciplinar escolar. Em vez da velha opção aprovação/reprovação, no culto da performance otimizada (EHRENBERG, 2010) produzem-se, interminavelmente, graus diferenciados e certamente mais sutis, mas não menos operantes, de reprovação ou de exclusão. A norma moderna estabelecia uma lógica dual. Na escola, por exemplo, o par “aprovação"|"reprovação", enquanto o desnorte contemporâneo dispensa a normatividade, apresentando-se como um horizonte infinito, inalcançável, de maximização de desempenhos. Daí seu funcionamento como dispositivo de exclusão em diversos graus, mesmo quando se apresenta como "avaliação de produtividade”. A avaliação compara para hierarquizar e, ao ranquear, promove a introjeção da lógica de funcionamento empresarial. Por isso, dispensa a normatividade disciplinar, que de certo modo atenua a competitividade, ao produzir conclusões de ciclos. No mesmo movimento, a norma perde seus contornos nítidos, volatiliza-se, dilata-se e se condensa na nuvem, inoculando nos corpos sensações de inadequação, tristeza, impotência. Eis uma das faces do que a pesquisadora Cristina Corrêa chamou de "sofrer por superfluidez" (CORRÊA apud SIBILIA, 2012, p. 204). Para esses sofrimentos e sensações oferecem-se proliferantes rubricas psiquiátricas, bem como novos produtos da indústria farmacêutica.

Passemos agora à nossa segunda referência teórico-filosófica para entendermos melhor o modo de operação e as implicações do regime de avaliação. Em uma publicação dedicada à Ideologia da avaliação em meios acadêmicos (ZARKA, 2009), Philippe Büttgen e Barbara Cassin salientam que a "avaliação", que deveria tão somente classificar, serve antes de mais nada para justificar desclassificações e desengajamentos do Estado (BÜtTgen e CASSIN, 2009). Para ambos os autores, o motor atual da avaliação gira em torno da noção de performance, termo que opera magicamente, transformando o "mais" em "melhor", a quantidade em qualidade, o cardinal em ordinal. Esse poder mágico derivaria de uma tensão interna à noção de 
performance, na medida em que o termo designa, ao mesmo tempo, o mais objetivamente mensurável - como no caso dos indicadores de desempenho de uma máquina ou de uma economia - e o aspecto mais singular de um ato individual, aquilo que não se repete - a performance de um cavalo, de um campeão. Em suma, através dessa palavra mágica, a qualidade torna-se uma propriedade emergente da quantidade (BÜTTGEN e CASSIN, 2009, p. 29).

Os autores também lembram que a "cultura de resultados", a lógica da "coopetição" (termo inquietante, fusão entre cooperação e competição) e o modelo de avaliação calcado na performance marcam a convergência e a circularidade entre novos sistemas de medição acadêmica e o programa Google. Este utiliza o algoritmo PageRank para hierarquizar a ordem das respostas na página, valendo-se do modelo acadêmico da citação. Os mais clicados são classificados em primeiro lugar, estabelecendo-se o império da doxa, que coloca na primeira colocação os sites mais citados... pelos sites mais citados. Ironicamente, Google caracteriza esse sistema como "democracia cultural" (BÜTTGEN e CASSIN, 2009, p. 29). Os pesquisadores são classificados pelo número de publicações em revistas que, por seu turno, são cotadas por outras revistas, também elas ranqueadas. Eis como são gerados novos labirintos kafkianos da quantificação produtivista ${ }^{2}$ e da opinião tautologicamente autocertificada. Note-se que subjaz à crença nesse regime de avaliação permanente a angústia de correr o risco de perder a corrida para competidores nacionais e internacionais. Em síntese, segundo os dois autores, o modelo utilizado alavanca uma "economia do conhecimento", uma knowledge-based society cuja história confunde-se com a das crises das bolsas de valores (BÜTTGEN e CASSIN, 2009, p. 35). Eis o valor preponderante: o mercado, suas leis e ritmos nervosos.

O diagrama da avaliação, ligado à quantificação e à lógica da exclusão, tem por efeito sugerir que a visada crítica e reflexiva - que se espraia no tempo e não se pauta pela imediatez de resultados quantificáveis - é anacrônica. A crítica reflexiva acaba por ser confundida com "julgamento", que, como tal, inscreve-se no campo da moral. Para desfazer esse mal-entendido, resta salientar, de modo breve, a visão nietzschiana de

2 Cabe lembrar que o penúltimo autor a receber o prêmio Camões de Literatura, Raduan Nassar, escreveu uma obra exígua, 2 livros (e meio, segundo ele mesmo), extremamente contundente - o que, por si só, funciona como uma forma de resistência à quantificação produtivista. 0 "sucesso" literário persiste como um modo de avaliar resistente às pressões do diagrama aqui tematizado. Pode, por isso, ser ativado como alerta e sugestão de outros parâmetros a partir dos quais se estimar valores. 
avaliação, radicalmente diversa do diagrama até aqui descrito, e sua distinção da noção de julgamento. Ressalte-se, de início, que não se deve confundir palavras e conceitos: embora o termo usado seja o mesmo ("avaliação"), o sentido será totalmente outro, uma vez remetido à filosofia nietzschiana. Para abordarmos a concepção nietzschiana, reportamo-nos sobretudo à Genealogia da moral.

Em sua obra, Nietzsche procede à avaliação dos valores, isto é, à estimação das forças e perspectivas que se expressam em determinados valores - sempre histórico-culturais, portanto particulares e cambiáveis. Em vez de discutir a suposta verdade ou universalidade dos valores, o filósofo avalia a que servem os valores criados, que efeitos eles têm sobre a vida dos homens e da terra. Para tal, lança mão de um critério particular, exposto com clareza e probidade: ele avalia valores a partir de um diagnóstico tanto das forças que os estabelecem quanto de seus efeitos, no sentido do favorecimento ou do enfraquecimento, do esmagamento da potência da vida. Arriscando uma etimologia fantasiosa, o filósofo ressalta que a palavra alemã para "ser humano", Mensch, teria sua origem etimológica na ação de medir (messen), de avaliar. Afirma, então, que toda vida humana não pode deixar de avaliar, de medir, de engendrar e inventar valores. Segundo Nietzsche, o homem é até mesmo capaz de suportar os maiores sofrimentos, contanto que estes tenham sentido. Se não os têm, trata de criá-los. Desfigurar os homens, eliminar sua humanidade é neles esmagar a possibilidade do sentido - como bem o souberam fazer, por exemplo (mas não apenas), os campos de concentração do Terceiro Reich. A genealogia convoca, portanto, a avaliação dos próprios quadros de valores, bem como a problematização dos interesses que eles expressam e dos efeitos realizadores que implicam. Mas avaliar, atribuir sentidos permanece indispensável na medida em que valores (que, evidentemente, são variáveis) demarcam territórios existenciais em que se instala toda vida humana. Quando não se julga, mas se avalia, parte-se necessariamente de certas apreciações acerca da vida e da história.

A avaliação nietzschiana, portanto, nada tem a ver com o diagrama da avaliação salientado no episódio de Black Mirror e neste artigo. Pelo contrário, a abordagem desse diagrama é atravessada pelo gesto de avaliação inspirado na perspectiva nietzschiana. Esse modo de avaliar tampouco se confunde com neutralidade ou isenção, no sentido de uma pretensa abstenção ante o valorar. Como humanos, sempre avaliamos, mesmo quando acreditamos na ficção de neutralidade. Resta salientar de que modo, para Nietzsche, avaliar não se confunde com julgar. Julgar pressupõe a referência a sentidos e valores já 
dados, estabelecidos de uma vez por todas, tomados como não interessados e supostamente universais. Estabelece uma coreografia na qual a instância judicativa se exclui do campo do debate e do embate ${ }^{3}$ o dedo em riste, apontando para o outro, é sua expressão mais evidente.

$\mathrm{O}$ ato de julgar, conforme mostrou Nietzsche na Genealogia no âmbito da moral, segue uma coreografia precisa: parte da negação do outro como mau, injusto, desonesto, o que tem por efeito reforçar a pretensa ingenuidade, pureza ou idoneidade daquele que emite o juízo. Tal gesto, sempre fundado na negatividade, remete ao deus judaico-cristão, à moral como um sistema de valores que se pretende não inventado e desinteressado. Está presente igualmente nas práticas políticas pautadas pelo esquema rudimentar eles/nós, muito manipulado politicamente, por seu aspecto tosco e simplificador.

A discussão acerca do tema ganha, atualmente, uma importância crucial, na medida em que o mecanismo do julgamento tem pautado a cena pública, tanto em redes sociais quanto em jogos políticos. Nietzsche e, em sua esteira, Antonin Artaud enfatizaram as violências do julgamento. Quando atualmente se confunde o exercício crítico com "julgamento", pretende-se, mesmo de modo inconsciente, enfraquecer e anular o movimento reflexivo, inserindo-o na camisa de força da moral, da crença em verdades únicas. Avaliar é um gesto mais complexo e nuançado. Foi o que procurei experimentar neste texto, que não pretende julgar a avaliação, mas estimar as forças que nela se exprimem e suas implicações para a vida e o pensamento.

\section{Referências}

BÜTTGEN, Philippe e CASSIN, Barbara.

"'J'en ai 22 sur 30 au vert'. Six thèses sur l'évaluation". In: ZARKA, Yves Charles (org.). Cités. L'idéologie de l'évaluation (la grande imposture). Vol. 37. Paris: PUF, 2009.

CRARY, Jonathan. Suspensions of perception: attention, spectacle and modern culture. Massachusetts: MIT Press, 1999.

DELEUZE, Gilles. Conversações. Rio de Janeiro: Ed. 34, 1992.

DEPRESSÃO cresce no mundo, segundo OMS; Brasil tem maior prevalência da América Latina, Rio de Janeiro, O Globo, 23/02/2017, p. 25.

EHRENBERG, Alain. O culto da performance: da aventura empreendedora à depressão nervosa. Aparecida, SP: Idéias \& Letras, 2010.

AUTOR. Ruminações: cultura letrada e dispersão hiperconectada. Rio de Janeiro: Garamond/FAPERJ, ANO. 
FOUCAULT, Michel. História da sexualidade

I (A vontade de saber). Rio de Janeiro:

Graal, 1980.

FREIRE FILHO (org.). Ser feliz hoje: reflexões sobre o imperativo da felicidade. Rio de Janeiro: Editora FGV, 2010.

GIL, José. Em busca da identidade - o

desnorte. Lisboa: Relógio d'Água, 2009.

NIETZSCHE, Friedrich. Genealogia da moral. Tradução de Paulo César de Souza. São Paulo: Companhia das Letras, 1998.

SIBILIA, Paula. Redes ou paredes: a escola em tempos de dispersão. Rio de Janeiro:

Contraponto, 2012.

ZARKA, Yves Charles (org.). Cités. L'idéologie de l'évaluation (la grande imposture). Vol. 37. Paris: PUF, 2009. 


\section{ON THE EVALUATION IMPERATIVE: through the dystopian mirrors of contemporary times}

\section{Abstract}

The episode of Black Mirror named "Nosedive" is the starting point for discussing of the contemporary imperative of evaluation. The media and technological means are not considered as "causes", but compatible with frames of life suitable to neoliberalism, to its values and logics. The article refers to both José Gil's discussion of the "evaluation diagram", and to Büttgen and Cassin's ponderings on academic performance evaluation. The diagram is then distinguished from the Nietzschean concept of evaluation, radically different from moral, mediatic and political judgement.

\section{Keywords}

Black Mirror. Diagram of evaluation. Nietzschean philosophy.

\section{IMPERATIVO DE EVALUACIÓN: espejos distópicos contemporáneos}

\section{Resúmen}

A partir del análisis del primer episodio de la tercera temporada de la serie Black Mirror ("Nosedive"), el artículo investiga la lógica de funcionamiento del dispositivo de evaluación, vinculado a las redes sociales. El tema de las tecnologías no es pensado como una causa, sino como adecuación a los estilos de vida atravesados por el capitalismo financierizado y el modelo de las empresas. Se refiere al "diagrama de evaluación" (José Gil), en sus mecanismos de exclusión matizados, así como a las reflexiones de Büttgen y Cassin sobre la evaluación del desempeño académico. Finalmente, distingue el diagrama de evaluación del sentido de evaluación nietzscheano, radicalmente diferente del "juicio" moral, mediático y político.

\section{Palabras clave}

Black Mirror. Diagrama de evaluación. Filosofía nietzscheana.

\section{Maria Cristina Franco Ferraz}

Doutora em Filosofia pela Universidade de Paris I Sorbonne, Paris, França. Professora titular da Escola de Comunicação da Universidade Federal do Rio de Janeiro, Rio de Janeiro, Rio de Janeiro, Brasil. E-mail: mcfferraz@hotmail.com 